\title{
Erratum to: Species distribution and in vitro antifungal susceptibility profiles of yeast isolates from invasive infections during a Portuguese multicenter survey
}

\author{
I. Faria-Ramos ${ }^{1} \cdot$ J. Neves-Maia ${ }^{1} \cdot$ E. Ricardo ${ }^{1}$. \\ J. Santos-Antunes ${ }^{1,2} \cdot$ A. T. Silva ${ }^{1,3,4} \cdot$ S. Costa-de-Oliveira ${ }^{1,3,4}$. \\ E. Cantón ${ }^{5}$ • A. G. Rodrigues ${ }^{1,3,4,6} \cdot$ C. Pina-Vaz ${ }^{1,3,4,7,8}$
}

Published online: 21 August 2015

(C) Springer-Verlag Berlin Heidelberg 2015

Erratum to: Eur J Clin Microbiol Infect Dis. 2014

Dec;33(12):2241-47

DOI: 1007/s10096-014-2194-8. Epub 2014

July 11

Study period reported in the originally published article had an error. Please find below the corrected text. Please note that this did not affect the conclusion of the published article.

The study period was 24 months, between January 1st 2010 and December 31st 2011. Death associated with fungemia was calculated using the author's hospital sample (104/240). Regarding mean incidence, it was calculated by making a ratio between the number of isolates received from each hospital by the number of patients admitted (published on Administração Central do Sistema de Saúde, http://www. acss.min-saude.pt/) during the same period of time. Ilse Fontes (Hospital de Santa Luzia, Elvas) is missing at Acknowledgments section.

The online version of the original article can be found at http:// dx.doi.org 10.1007/s10096-014-2194-8.

C. Pina-Vaz

cpinavaz@yahoo.com

1 Microbiology Department, Faculty of Medicine, University of Porto, Porto, Portugal

2 Gastroenterology Department, Faculty of Medicine, Centro Hospitalar de São João, Porto, Portugal

3 Cardiovascular Research \& Development Unit, Faculty of Medicine, University of Porto, Porto, Portugal
4 CINTESIS - Center for Health Technology and Services Research, Faculty of Medicine, University of Porto, Porto, Portugal

5 Unidad de Microbiología Experimental, Centro de Investigación, Hospital La Fe, Valencia, Spain

6 Burn Unit, Centro Hospitalar de São João, Porto, Portugal

7 Clinical Pathology Department, Centro Hospitalar de São João, Porto, Portugal

8 Clinical Pathology Department, Faculty of Medicine, University of Porto, Alameda Professor Hernâni Monteiro, 4200-319 Porto, Portugal 